\title{
THE METHOD OF INTERPRETATION OF SYEH MUHAMMAD ABDUH AND SYEH RASYID RIDHA IN THE BOOK TAFSIR AL MANAR
}

\author{
Moh. Zaini \\ Email: mzainidahlan5 $\overline{6}$ gmail.com \\ Sekolah Tinggi Ilmu Al-Qur'an Wali Songo Situbondo
}

\begin{abstract}
Abstrac
This article discusses the interpretation motto of Syeh Muhammad Abduh and Syeh Rasyid Ridha whose interpretive pattern has a great influence on the thinking of Islamic reforms in its time and time. By using the comparative method the writer tries to find out the uniqueness of each interpreter both the similarities and the differences. The result can be understood that the two exegetes have interpretive methods and styles which must be different. Al-Manar's interpretation is the greatest work of two figures who are very well known in Muslim intellectuals, he is Syeh Muhammad Abduh as the teacher, and Syeh Rasyid Ridha as a student, in answering various problems with the discourse of contextualizing the interpretation of the verses of the Qur'an ' in the Tafsir Al-Manar Book. Regarding the method he uses in interpretation has many similarities between Syeh Muhammad Abduh and Syeh Rasyid Ridha. Keywords: method, interpretation, interpretation
\end{abstract}

\section{A. Pendahuluan}

Ilmu tafsir sebagai upaya memahami dan menjelaskan makna ayat-ayat al-Qur'an telah melahirkan banyak karya tafsir.Dinamika kegiatan penafsiran tersebut berkembang seiring dengan tuntutan zaman.Keanekaragaman latar belakang individu dan kelompok manusia turut memperkaya terhadap penafsiran yang ada. ${ }^{1}$ Salah satunya yang berkembang dalam penafsiran saat ini adalah bagaimana membumikan al-Qur'an yang akan datang dari 'langit', atau dalam artian bagaimana memahami al-Qur'an secara kontekstual. Pemahaman al-Qur'an secara kontekstual itu merupakan kebutuhan umat islam dalam menghadapi dinamika perkembangan zaman dan juga sekaligus merupakan bukti bahwa Al-Qur'an memang sebagai petunjuk yang bisa operasional dalam berbagai situasi ruang dan waktu. Kontekstualisasi al-Quran sesungguhnya sudah lama dilakukan oleh umat Islam. Hal ini terbukti dengan munculnya kitab-kitab tafsir dengan ciri khasnya masing-masing dalam rangka merespon berbagai persoalan yang berkembang pada zamannya.Metode tafsir yang seperti inilah yang kemudian oleh J.M.S Baljon disebut sebagai corak tafsir modern.Dalam sejarah perkembangan penafsiran al-

\footnotetext{
${ }^{1}$ Charles Kurzman, Wacana Islam Liberal (Jakarta: Paramadina, 2001), hlm. 210
} 
Quran, terdapat suatu gagasan utama yang selalu dicetuskan oleh para tokoh pembaharu atau modernis, yaitu kembali kepada al-Qur'an dan Hadis. Di antaranya adalah Syeh Muhammad Abduh dan Syeh Rasyid Ridha yang dengan sungguhsungguh mengajak untuk kembali kepada al-Qur'an dan berpegang teguh dengannya, dan perlunya penafsiran/interpretasi baru terhadap ajaran-ajaran dasar Islam, sesuai dan sejalan dengan tuntutan dan perkembangan zaman. ${ }^{2}$ Demikian penting upaya memahami dan merenungkan kandungan ayat-ayat al-Qur'an, demi mendapatkan pelajaran-pelajaran berharga darinya dan kebangkitan atau kemajuan umat Islam sesungguhnya sangat tergantung pada sejauh mana mereka berpedoman dan berpegang teguh pada petunjuk-petunjuk, ajaran-ajaran, aturan-aturan, serta norma-norma al-Qur'an yang mencakup segala aspek dan sisi kehidupan manusia. Bagi Syeh Muhammad Abduhdan Syeh Rasyid Ridha, tafsir al-Qur'an seharusnya berfungsi sebagai alat penggugah kesadaran manusia agar menjadikan al-Qur'an sebagai sumber hidayah.Semangat beliau untuk menjadikan al-Qur'an sebagai petunjuk manusia inilah yang menjadikan penafsirannya berbeda di antara kalangan mufassir kontemporer (mutaakhkhirin) dengan mufassir terdahulu (mutaqaddimin).Dalam upaya mengembalikan Al-Qur'an sebagai hudallinnats, AlQur'an dipahami sebagai kitab suci yang kemunculannya tidak bisa dilepaskan dari konteks kesejarahan umat manusia. Al-Qur'an adalah kitab suciyang sesuai untuk segala zaman dan tempat, kitab suci yang berlaku secara universal yang melampaui batas ruang dan waktu. ${ }^{3}$

\section{B. Pembahasan}

\section{Pemikiran Syehmuhammad Abduh}

\section{a. Ide-Ide Pembaruan Syeh Muhammad Abduh}

Abduh sebagai seorang intelektual dan sarjana muslim populer, hidupnyaselalu diwarnai dengan gairah dalam menuntut ilmu. Ia juga pernah menjadi murid Al-Afghani seorang pendiri Pan Islamisme yang waktu itu sempat

\footnotetext{
${ }^{2}$ Rif'at Syauqi Nawawi, Rasionalitas Tafsir Syeh Muhammad Abduh (Jakarta: aramadina, 2002), hlm. 5

${ }^{3}$ Ahmad Izzan, Metodologi Ilmu Tafsir (Bandung: Tafakur, 2011), hlm. 210
} 
singgah di Kairo. Tak dipungkiri jika gagasan-gagasannya banyak dipengaruhi oleh pemikiran gurunya itu. ${ }^{4}$

Adapun gagasan yang dikeluarkan dalam pemikiran Syeh Muhammad Abduh adalah sebagai berikut :

1) Membuka Pintu Ijtihad

Pemikiran Abduh sejalan dengan pemikiran Al-Afghani yakni penyebab kemunduran umat Islam pada akhir abad pertengahan adalah sikap jumud.Dalam sikap ini mengandung arti keadaan membeku, statis, berpegang teguh pada adat.Akibat dipengaruhi sikap jumud umat Islam tidak menghendaki perubahan dantidak mau menerima perubahan.Timbulnya sikap jumud berawal dari tradisiorang-orang nonIslam dengan tetap membawa adat istiadat dan paham-paham animistis.Kelompok ini besar pengaruhnya terhadap umat Islam yang mereka perintah. Di samping itu, raja-raja dari Dinasti Mamluk menghindari ilmu pengetahuan, karena ilmu pengetahuan akan membuka mata rakyat yang dikhawatirkan akan memberontak. ${ }^{5}$

Menghadapi keadaan masyarakat yang jumud dan penuh khurafat tersebut, Abduh bangkit dengan ide kembali kepada nilai-nilai yang terkandung dalam Al-Qur'an dan hadits, sebagai ide pemurniannya Abdul Wahab. Bagi Abduh tidak cukup hanya kembali kepada ajaran-ajaran yang asli itu, sebagai yang dianjurkan oleh Muhammmad Abd al-Wahab, karena zaman saat ini umat Islam sekarang mengalamiperubahanzaman klasik menuju zaman modern, ajaran-ajaran asli itu perlu disesuaikan dengan keadaan modern sekarang. Penyesuaian itu menurut Abduh dapat dijalankan.Paham Ibn Taimiyah bahwa ajaran-ajaranIslam terbagi dalam dua kategori, ibadat dan muamalah (hidup kemasyarakatan manusia) diambil dan ditonjolkan Abduh.Ia melihat bahwa ajaran-ajaran yang terdapat dalam Al-Quran dan hadis mengenai ibadat bersifat tegas, jelas dan terperinci. Sebaliknya ajaran-ajaran mengenai hidup kemasyarakatan

\footnotetext{
${ }^{4}$ Abdillah F. Hasan, Tokoh-Tokoh Mashur Dunia Islam (Surabaya: Jawara Surabaya,2004), hlm. 259

${ }^{5}$ Risan Rusli, Pembaharuan Pemikiran Modern Dalam Islam (Jakarta: Rajawali Press, 2014), hlm 103
} 
umat hanya merupakan dasar-dasar dan prinsip-prinsip umum yang tidak terperinci.

Seterusnya ia melihat bahwa ajaran-ajaran yang terdapat dalam AlQur'an dan hadits mengenai soal-soal kemasyarakatan itu, hanya sedikit jumlahnya. Karena prinsip-prinsip itu bersifat umum tanpa perincian.Abduh berpendapat bahwa semua itu dapat disesuaikan dengan tuntutan zaman.

Dalam gerakannya, ia sangat menentang taklid, karena taklid menurutnya adalah salah satu sebab penting yang membawa kemunduran umat Islam abad 19 dan 20. Ia mengkritik para ulama yang mengajarkan bahwa umat Islam belakangan wajib mengikuti hasil ijtihad ulama terdahulu, hal ini menurutnya, akan membawa kepada tidak berfungsinya akal, sehingga menghambat perkembangan bahasa, organisasi sosial, hukum, lembaga-lembaga pendidikan dan lain sebagainya. ${ }^{6}$

Alasan Abduh membuka pintu ijtihad dan memberantas taklid adalah karena ia percaya pada daya kekuatan akal.Menurutnya, Al-Quran berbicara bukan semata kepada hati manusia, tetapi juga pada akalnya.Islam memandang akal mempunyai kedudukan tinggi.Allah menunjukkan perintah-perintah dan larangan-larangan-Nya kepada akal.Oleh sebab itu, Islam baginya, adalah agama yang rasional.Mempergunakan akal adalah salah satu dari dasar-dasar Islam.Iman seseorang tidak sempurna kalau tidak didasarkan pada akal.Dalam Islam-lah agama dan akal untuk pertama kali mebgikat tali persaudaraan. Bagi Abduh, akal mempunyai kedudukan tinggi. Wahyu tidak dapat membawa hal-hal yang bertentangan dengan akal. Kalau zahir ayat bertentangan dengan akal haruslahdicari interpretasi yang membuat ayat itu sesuai dengan pendapat akal.Kepercayaan pada kekuatan akal adalah dasar peradaban suatu bangsa. Akal yang terlepas dari ikatan tradisi akan dapat memikirkan dan memperoleh jalan yang membawa kepada

\footnotetext{
${ }^{6}$ Makrum, Teologi Rasional: Telaah atas Pemikiran Kalam Syeh Muhammad Abduh, JurnalStudi Keislaman Ulumuna, Vol. XIII No. 2 (Desember 2009). hlm 282.
} 
kemajuan dan ilmu pengetahuan. ${ }^{7}$ Untuk dapat menemukan formulasi dalam menyesuaikan ajaran-ajaran asli dengan situasi modern, maka perlu diadakan interpretasi baru dan perlu membuka pintu ijtihad.Ijtihad menurut pendapatnya bukan hanya boleh, justru penting dan perlu diadakan.Tetapi yang dimaksud bukan setiap orang boleh melakukan ijtihad.Hanya orangorang yang memenuhi syarat-syarat yang diperlukan yangboleh mengadakan ijtihad. Apabila tidak memenuhi syarat-syarat, maka harus mengikuti pendapat mujtahid yang ia setujui pahamnya. Ijtihad ini dijalankan langsung pada Al-Quran dan hadis, sebagai sumber yang asli dari ajaran-ajaran Islam.Dibukanya pintu ijtihad dengan sendirinya taklid kepada ulama tak perlu dipertahankan bahkan mesti diperangi karena taklid inilah yang membuat umat Islam berada dalam kemunduran dan tidak dapat maju.

Pendapat tentang pembukaan pintu ijtihad dan pemberantasan taklid berdasarkan atas kepercayaanya pada kekuatan akal.Menurut pendapatnya Al-Qur'an berbicara bukan semata kepada hati manusia, tetapi juga kepada akalnya.Islam memandang akal mempunyai kedudukan tinggi.Allah menunjukkan perintah-perintah dan larangan-larangan-Nya kepada akal.Mempergunakan akal adalah salah satu dari dasar-dasar Islam.Iman seseorang tidak sempurna kalau tidak didasarkan pada akal.Kepercayaan pada kekuatan akal membawa Abduh selanjutnya kepada paham bahwa manusia mempunyai kebebasan dalam kemauan dan perbuatan.Pembahasan tentang jumud mau tak mau akan menarik keluar persoalan tentang perkembangan pendidikan di Mesir itu sendiri. Sebagai konsekuensi dari pendapatnya bahwa umat Islam harus mempelajari dan mementingkan ilmu pengetahuan, umat Islam harus pula mementingkan soal pendidikan.Sekolah-sekolah modern perlu dibuka, di mana ilmu-ilmu pengetahuan modern diajarkan di samping pengetahuan agama.Al-Azhar pun perlu dimasukkan ilmu-ilmu modern, agar ulama-ulama Islam mengerti kebudayaan modern dan dengan demikian dapat mencari penyelesaian yang baik bagi persoalan-persoalan yang timbul dalam zaman modern ini.

${ }^{7}$ Makrum, Teologi Rasional: Telaah atas Pemikiran Kalam Syeh Muhammad Abduh, hlm 292 


\section{2) Rekonstruksi Pendidikan}

Terjadinya kontak hubungan antara Islam dengan Barat merupakan faktoreksternal pembaruan pendidikan Islam karena kaum muslimin dapat melihat kemajuan yang diraih Barat pada peralatan militer, ilmu pengetahuan dan teknologi. Misalnya, pendudukan atas Mesir oleh Napoleon pada tahun 1798 M., merupakan tonggak sejarah bagi umat Islam untuk mendapatkan kembali kesadaran akan kelemahan dan kemunduran mereka khususnya dalam bidang teknologi. ${ }^{8}$ Munculnya ide-ide pendidikan Abduh tampaknya lebih dilatarbelakangi oleh faktor situasi, yaitu situasi sosial keagamaan dan situasi pendidikan yang ada pada saat itu.Yang dimaksud dengan situasi sosial keagamaan dalam hal ini adalah sikap yang umumnya diambil oleh umat Islam di Mesir dalam memahami dan melaksanakan ajaran agama dalam kehidupan mereka sehari-hari. Sikap tersebut tampaknya tidak jauh berbeda dari apa yang dialami umat Islam di bagiandunia Islam lainnya.

Pemikiran yang statis, taqlid, bidah, dan khurafat yangmenjadi ciri dunia Islam saat itu juga berkembang di Mesir.Abduh memandang pemikiran yang jumud itu telah merambat dalam berbagai bidang, bahasa, syariah, akidah dan sistem masyarakat. ${ }^{9}$ Dunia pengabdiannya sebagai seorang pendidik ia rintis di Al-Azhar. Gebrakan pembaruan pertamanya mengusulkan perubahan terhadap Al-Azhar.Abduh berusaha untuk merombak sistem pendidikan yang ada saat itu, di mana terjadi dualisme sistem kependidikan, yaitu Metode pendidikan yang dilaksanakan di sekolah-sekolah modern, baik yang dibangun oleh pemerintah Mesir maupun sekolah yang dibangun oleh bangsa asing, dan Metode sekolah agama yang bersifatdoktrinal dan tradisional. Ia yakin, apabila Al-Azhar diperbaiki, kondisi kaum muslimin akan membaik. Al-Azhar, dalam pandangan Abduh, sudah saatnya untuk berbenah dan karena itu perlu diperbaiki, terutama dalam masalah administrasi dan pendidikan di

\footnotetext{
${ }^{8}$ Nasrudin Yusuf, Perbandingan Pemikiran Syeh Muhammad Abduh dan Rasyid Ridho tentang Pendidikan,Jurnal Sosial Budaya, Vol. 8, No. 01 (Januari-Juni 2011). Hlm 64.

${ }^{9}$ Maslina Daulay, Inovasi Pendidikan Islam Syeh Muhammad Abduh, Jurnal Ilmu Pendidikan dan KeislamanDarul Ilmi, vol.01 No. 02 (Juli 2013). hlm 89.
} 
dalamnya, termasuk perluasan kurikulum, mencakup ilmu-ilmu modern, sehingga Al-Azhar dapat berdiri sejajar dengan universitas-universitas lain serta menjadi mercusuar dan pelita bagi kaum Muslimin pada zaman modern. ${ }^{10}$

\section{3) Tafsir Al-Qur'an}

Al-Quranul Karim adalah sumber tasyri pertama bagi umat Nabi Muhammad serta menjadi kebahagiaan mereka terhadappemahaman makna, pengetahuan rahasia-rahasia dan pengalaman apa yang terkandung di dalam Al-Qur'an. Kemampuan setiap orang dalam memahami lafaz dan ungkapan Al-Qur'an tidaklah sama. Padahal penjelasannya sedemikian gamblang dan ayat-ayatnya pun sedemikian rinci.Perbedaan daya nalar diantara mereka adalah suatu hal yang tidak dipertentangkan lagi.Kalangan awam hanya dapat memahami makna-maknanya yang zahir dan pengertian ayat-ayatnya secara global. Sedang kalangan cerdik cendekia dan terpelajar akan dapat menyimpulkan pula daripadamakna-makna yang menarik. ${ }^{11}$ Rencana pembaharuan politik dan sosial Abduh adalah menjadikan reinterpretasi Al-Qur'an untuk dunia modern sangat penting.Ia merasa bahwa Al-Qur'an harus memainkan peranan sentral dalam mengangkat masyarakat, memperbarui kondisi umat, dan menyodorkan peradaban Islam modern. Dengan demikian dia dapat menafsirkan Islam sebagai kampiun kemajuan danpembangunan. Katanya kembali ke nashAlQur'an itu perlu, dengan melepaskan nash dari ulasan yang diulang-ulang dan terkadang bertentangan Abduh memimpin upaya membuat nash dapat dimengerti oleh semakin banyak orang terdidik yang mampu membaca dan merenungkan makna serta pesannya.

4) Tafsir Al-Manar

Tafsir al-Manar adalah salah satu tafsir Al-Qur'an modern yang sangatterkenal di kalangan umat Islam. Kehadirannya bagaikan oase di

\footnotetext{
${ }^{10}$ Luk-Luk Nur Mufidah, Konsep Pendidikan Islam Perspektif Filosof Muslim Dan Praktisi Abad Modern: Syeh Muhammad Abduh dan Muhammad Iqbal, Jurnal Ilmu Tarbiyah At-Tajdid, Vol. 2 No. 2, (Juli 2013). hlm 174.

${ }^{11}$ Ilyas Daud, Pemikiran Syeh Muhammad Abduh Tentang Al-Quran Tafsir, Jurnal Ushuluddin dan Pemikiran Islam Farabi,Vol. 10 No. 1 (Juni 2013). hlm 15
} 
tengah padangpasir nan tandus. Sejak awal kemunculannya ketika masih diterbitkan secara berkala dalam bentuk artikel di majalah selalu ditunggu oleh banyak pembaca yang haus siraman petunjuk Al-Qur'an. Nama alManar sebenarnya bukan namaasli dari karya bersama Syeh Muhammad Abduh dan Muhammad Rasyid Ridha ini.

Nama Al-Manar adalah nama populer yang dinisbatkan kepada nama majalah dimana tafsir tersebut diterbitkan secara berkala. Nama yang diberikan ketika diterbitkan dalam bentuk tafsir adalah Tafsir Al-Qur'an Al-Hakim.Dalam muqaddimah Tafsir Al-Manar diperkenalkan bahwa tafsir ini sebagai satu-satunya kitab tafsir yang menghimpun riwayat-riwayat yang shahih dan pandangan akal tegas yang menjelaskan hikmah syariah serta sunnatullah terhadap manusia, dan menjelaskan fungsi Al-Qur'an sebagai petunjuk (hidayah) untuk seluruh manusia di setiap waktu dan tempat.Uraian dalam tafsir ini menggunakan redaksi atau kalimat-kalimat yang mudah dan berusaha menghindari istilah-istilah ilmu yang bersifat teknis sehingga dapat dimengerti oleh orang awam tetapi juga dapat memenuhi kebutuhan dan dapat dikonsumsi oleh orang-orang khusus (cendekiawan).

Dalam menafsirkan Al-Qur'an Syeh Muhammad Abduh menggunakan metode (manhaj) tersendiri yang berbeda dengan metode tafsir yang digunakan para ahlitafsir dari kalangan salaf al-shalih (ulama salaf).Perbedaan tersebut terjadi pertama-tama karena pengaruh latar belakang kultural dan intelektual.Jika ulama salaf menafsirkan Al-Qur'an ketika umat Islam betul-betul menjadikan Al-Qur'an sebagai pedoman hidup (al-dustur) dalam kehidupan mereka, sehingga tafsir Al-Qur'an bagi mereka adalah tujuan (ghayâh).Sedangkan Abduh menafsirkan Al-Qur'an pada saat umat Islam tidak secara serius berhukum dengan hukum-hukum Al-Qur'an, sehingga tafsir Al-Qur'an merupakan alat untuk perbaikan kondisi masyarakat (umat Islam), bukan sebagai tujuan itu sendiri.

\section{b. Karya-karya Syeh Muhammad Abduh}


Karya-karya Abduh sangat banyak dan bervariasi tipologi pembahasannya.Selain karangan-karangannya yang terdapat dalam surat kabar dan majalah seperti harian resmi dari pemerintah Mesir al-Waqai Al Mishriyah, harian umum Al Ahram, Al Urwatul Wustqa, yang dipimpinnya sendiri ketika di Paris, Tsamaratul Funun, yang terbit di Beirut, Al Muayyad dan Al Manar, di bawah pimpinan Rasyid Ridha.

Selain berupa majalah dan koran, Abduh juga menerbitkan buku-buku yang terkenal, yaitu: Risalah Al Waridah, Cairo 1874, tentang tasawuf dan mistik, Hasyiyah ala Syarh ad Dawani lil aqaidil adudidyah, Cairo 1876-1904, Risalah Ar Rad alad Dahriyin, terjemahan dari karangan Al-Afghani, terbit di Beirut 1886, di Mesir 1895, Syarh Nahjul Balaghah, uraian karangan Sayidina Ali, Khalifah ke IV, terbit di Beirut 1885, Syar Maqamat Badi Az Zaman al Hamadhani, Beirut 1889, Risalah At Tauhid, Cairo 1897, yang bercatatan Rasyid Ridha, Cairo, 1908. Syarh Kitab Al Basier an-Nasyriah fi ilmi al Mantiq, tentang pengetahuan dan logika, Cairo 1898, Taqrir fi Islah al-Mahakim asy-Syariyah, kehakiman di Mesir, karangan yang diterjemahkann dari A Muajjad, yang ditujukan untuk menangkis serangan G. Hanotaux, diterjemahkan ke dalambahasa Prancis dengan nama L Europe et L Islam, Cairo, 1905, oleh M. Thallat Harb Bey, Al Islam wa Nasraniya maal Ilm wal Madaniyah, beberapa kali terbit di Cairo 1902, kedua juga tahun 1905, Tafsir juz Amma, Cairo 1904, Tafsir Surat Al-Ashr, sebagai kitab di Cairo, 1915, begitu juga kemudian diterbitkan oleh Rasyid Ridha manuskrip-manuskrip yang tertinggal, seperti: Risalah Wahdatul Wujud,Tarikh Ismail Pasha, Filsafat al-Ijtimai wat Tarikh, NizamatTarbiyah al-Misriyah, Tarikh Asbab As Tsaurah Al Arabiyah dan lain-lain. ${ }^{12}$

\section{c. Perbandingan dalam pemikiran Syeh Muhammad Abduh dan Syeh Rasyid Ridha \\ Mengenai metode yang dipakainya dalam penafsiran banyak memiliki persamaan antara Syeh Muhammad Abduh dan Syeh Rasyid Ridha. Dalam penafsirannya, ia tidak terikat pada mufassir lain, tidak harus menyesuaikan}

12 Imam Muhsin, Perubahan Budaya dalam Tafsir Al-Quran: Telaah Terhadap Penafsiran Syeh Muhammad Abduh dalam Tafsir Al-Manar, Jurnal Thaqafiyyat, Vol. 16 No. 2 (Desember 2015),.hlm 126. 
makna nash Al-Qur'an dengan akidah atau pendapatnya sendiri, tidak pula menggunakan hadis-hadis palsu, tidak menggunakan cerita-cerita Israiliyat, ayatayat mubham tidak pernah ditentukan maknanya, dan menghindarkan diri dari istilah-istilah ilmu pengetahuan.

Dalam penafsirannya dia selalu berusaha dengan keras mengungkapkan makna Al-Qur'an dengan susunan bahasa yang mudah diterima, menjelaskan kesulitan-kesulitannya, membela Al-Qur'an dengan menghilangkan keraguan terhadapnya, menerangkan hidayah dan hikmahnya serta berusaha memecahkan problem kemasyarakatan secara metodis

\section{Pemikiran Syeh Rasyid Ridha}

\section{a. Pemikiran Pembaruan Syeh Rasyid Ridha}

Untuk membicarakan pemikiran pembeharu yang di cetuskan oleh Syeh Rasyid Ridha perlu di bahas tentang beberapa kajian yang meliputiaspek-aspek teologi, syariat dan pendidikan.

1) Kemurnian Aqidah

Syeh Rasyid Ridha hidup dalam kurung waktu 1282 H/1863M-1354H/1935M dalam suasana politik pemerintahan kerajaan usmani. Pemikiranya yang berkaitan dengan teologi terutama mengajak umat Islam kembali ke zaman awal di saat umat Islam masih memiliki akidah yang murni.Zaman ini disebut dengan zaman salaf yang meliputi masa rasul dan sahabat.Akidah Islam pada saat itu masih belum tercemar oleh unsur-unsur tradisri dan pemikiran filosofis.Pemahaman terhadap agama mereka masih bersandar pada sumber yang utentik yaitu Al-Qur' an dan hadits. ${ }^{13}$

2) Akal dan wahyu

Kajian teologis berkenaan dengan akal dan wahyu di kalangan mutakallimin mempermasalahkan kesanggupan akal dan fungsi wahyu terhadap persoalan pokok Islam dalam agama yaitu Tuhan serta kebaikan dan kejahatan.Dalam menjawab keempat pertanyaan tersebut kaum teolog terbagi dua aliran yaitu aliran rasioanal dan aliran tradisional.kalangan aliran rasional

\footnotetext{
${ }^{13}$ Muhaimin, Pembaharuan Islam: Repleksi Pemikiran Rasyid Ridha dan Tokoh-Tokoh Muhammadiyah,
} (Yogyakarta: Pustaka Dinamika, 2000). Hlm 18. 
seperti Mu'tazilah dan Maturidiah Samarkand menempatkan akal sebagai mempunyai daya yang kuat.Sedangkan bagi kalangan aliran tradisional seperti Asy'ariah dan maturidia Bukhara menempatkan akal daya yang lemah.

Intensitas kekuatan akal dalam mengkaji masalah-masalah ketuhanan terutama untuk menjawab empat macam pertanyaan sebaimana dinyatakan Harun Nasution sebagai berikut: Kalau kita selidiki buku-buku klasik tentang ilmu kalam akan kita jumpai bahwa persoalan kekuasaan dan fungsi wahyu ini dihubungkan dengan dua masalah pokonya masing-masing bercabang dua. Maslah pertama di hubungakan dengan dua masalah yang masing-masing bercabang dua.

Masalah pertama ialah soal pnegetahuan Tuhan dan masalah kedua soal baik dan jahat.Masalah pertama bercabang dua menjadi mengetahui Tuhan dan kewajiban mengetahui Tuhan, yang dalam istilah Arab disebut husnul ma'rifat Allah dan wujud ma'rifat Allah. Kedua cabang dari masalah ialah mengetahui baik dan jahat dan kewajiban mengerjakan perbuatan baik dan menjauhi perbuatan jahat atau ma'rifat husn wa al qubh dan wujud ub I'tin'aq al hasan wa ijtin'ab al qabih yang juga disebut al-tahs in wa al taqb'in. ${ }^{14}$

Polemik yang terjadi di kalangan Islam rasional dan tradisional terhadap empat persoalan ketuhanan tersebut terutama mencakup manakah yang dapat diperoleh dengan akal dan mana yang diperoleh melalui wahyu.Pemikiran Rasyid Rida dalam aspek ketuhanan menghendaki agar urusan keyakinan mengakui petunjuk dari wahyu.Sungguhpun demikian akal tetap diperlukan untuk memberikan penjelasan dan argumentasi terutama kapada mereka yang masih ragu-ragu. Dengan kat lain Rasid Rida melihat wahyu mempunyai fungsi yang sangat penting untuk memahami persoalan-persoalan pokok dalam agama. Pada sisi lain akalpun memeiliki kesanggupan untuk memperoleh pemahaman terhadap persoalan-persoalan pokok keagamaan karena pada dasarnya wahyu member motivasi agar manusia menggunakan akalnya serta mencelah mereka yang memiliki keyakinan terhadap Tuhan tampa dibarengi dengan argumen-argumen rasional yang kuat.

\footnotetext{
${ }^{14}$ Muhammad Yusran Asmuni, Pengantar Studi Pemikiran dan Gerakan Pembaharuan dalam Dunia Islam, (Surabaya : al-Ikhlas, 1994). hlm 85.
} 


\section{3) Sifat Tuhan}

Bagi Syeh Rasyid Ridha, dengan memahami teks Al-Qur'an yang berkenaan dengan soal Tuhan dapat dipahami bahwa Tuhan itu mempunyai sifat, sebagaimana halnya dengan pandangan golongan salafiah Ahmad Ibnuhambal dan Ibnu Taimiah. ${ }^{15}$ Oleh karean itu, dalam memahami sifat Tuhan, Rasyid Rida memiliki corak teologi Asy'ariyah. Namun demikian terdapat perbedaan dalam memberikan interpretasi tentang sifat-sifat Tuhan Asy'ariah menyikapi sifat Tuhan dengan pandangan bili kaifa (tampa perlu memberikan takwil) dan demikian pula Ahmad Ibn Hambal.Pemahaman Rasyid Rida terhadap sifatsifat Tuhan pada dasarnya mengaku dan menetapkan adanya sifat(isba'at alsifat). Ia menyebut bahwa sifat-sifat Tuhan itu tergambar dalam al-asma' alhusn'a.

4) Perbuatan Manusia

Perbuatan Manusia, menurut Syeh Rasyid Ridha sudah dipolakan oleh suatu hukum yang telah ditetapakan Tuhan yang disebut sunnatullah, yang tidak mengalami perubahan. Berkenaan dengan sunnatullah, Syeh Rasyid Ridha menjelaskan sebaimana berikut:"bahwa Allah SWT membuat aturan-aturan tentang penciptaan-penciptaan atau kejadian-kejadian yang memberikan petunjuk kepada manusia sebagai hukum umum yang menjelaskan tentang sebab-sebab dan musabab-musabab. Hal itu tidakada perbedaan antara satu dengan yang lainnya. ${ }^{16}$

\section{Contoh Penafsiran Syeh Rasyid Ridha dalam Tafsir Al-Manar}

Contoh yang dikemukakan di sini adalah penafsiran Syeh Rasyid Ridha terhadap surat Al-an'am : 32 :

Artinya: "dan Tiadalah kehidupan dunia ini, selain dari main-main dan senda gurau belaka"

\footnotetext{
${ }^{15}$ A. Athaillah, Aliran Akidah Tafsîr al-Manar, (Banjarmasin: Balai Penelitian IAIN Antasari, 1990). Hlm 13

${ }^{16}$ Muhaimin, Pembaharuan Islam: Repleksi Pemikiran Rasyid Ridha dan Tokoh-Tokoh Muhammadiyah, $\mathrm{H} \operatorname{lm} 40$
} 
Makna diatas dijelaskan oleh Syeh Rasyid Ridha bahwa "Suatu perbuatan yang dilakukan oleh pelakunya bukan untuk suatu tujuan yang wajar, yakni mengakibatkan manfaat atau mencegan madharat"Selanjutnya, dukutipnya pendapat Ar-Raghib Al-Asfahani serta pengarang kitab Lisan Al-Arab (Ibnu Manzur) kemudian disusul dengan kesimpulan sementara bahwa Al-Lahwu jika disebutkan tanpa dibarengi oleh suatu kata, maka ia berarti segala sesuatu yang menyibukkan seseorang dari kesulitan-kesulitan yang dihadapinya atau kesedihan-kesedihannya; kesibukan tersebut dapat berupa permainan, nyanyian, atau apa saja yang mendatangkan kegembiraan.

Pengertian ini menurut Syeh Rasyid Ridha selanjutnya dapat lebih luas lagi sehingga ia terkadang berarti segala sesuatu yang menyenangkan dan menggembirakan walaupun bukan dengan tujuan menyibukkan diri dari sesuatu yang lebih penting dan berguna. ${ }^{17}$ Menurut Syeh Rasyid Ridha, sebagian besar mufassir tidak memberikan perhatian menyangkut perbedaan redaksi tersebut karena mereka beranggapan bahwa huruf wa (dan) hanya sekedar "menghimpun antara apa yang disebut pertama dengan yang disebut sesudahnya" tanpa mengandung suatu rahasia mengapa kata ini didahulukan atau dikemudiankan.

Menyangkut hal ini dikutipnya pendapat-pendapat Al-Alusy, Al-Khatib AlIskafy, kemudian dikemukakan pandangannya. Menurut Syeh Rasyid Ridha, mencari rahasia didahulukannnya Al-La'ibu atau Al-Lahwu tidaklah merupakan hal yang sulit, bahkan tidak perlu dipertanyakan karena hal tersebut merupakan urutan-urutan kronologis yang wajar bagi kehidupan manusia.

\section{Perbandingan Pemikiran Syeh Muhammad Abduh Dan Syeh Rasyid Ridha}

Pengaruh Pemikiran Syeh Muhammad Abduh dan Syeh Rasyid Ridha di Indonesia mendapat sambutan dari sejumlah tokoh pembaharu.Syeh Rasyid Ridha sebagai muridnya meneruskan gagasan Syeh Muhammad Abduh melalui majalah "Al-Manar" dan Tafsir "Al-Manar". Kemudian muncul pula Kasim Amin dengan bukunya "Tah'rr al-Marah", Farid Wajdi dengan bukunya "Dairat al-Ma'arif”, Syekh Thanthawi melalui karangannya "al-Taj al-Marshush bi alJawahir al-Quran wan al-‘Ulum”, Syekh Ali Surur al-Zankaluni, Syekh Musthafa

${ }^{17}$ Harun Nasution, Pembaharuan dalam Islam: Pemikiran dan Gerakan, 1992, hlm. 69. 
al-Maraghi, Syekh Muhammad Bakhit pengarang yang mementingkan dalam soal agama. Muhammad Farid Wajdi dan Syekh Thantawi Jawhari, penulis-penulis yang mementingkan soal kemasyarakatan, seperti : Qasim Amin, pemimpinpemimpin politik, seperti Sa'ad Zaghlul dan Ahmad Luthfi al-Sayyid dan sastrawan Arab, seperti Ahmad Taimur, al-Sayyid Musthafa Lutfi al-Manfaluthi, dan Muhammad Hafiz Ibrahim. ${ }^{18}$

Demikian juga, seperti Husein Haykal, Abbas Mahmud al-Aqad, Ibrahim Abdul Qadir al-Mazin, bahkan juga karangan Syeh Muhammad Abduh sendiri banyak diterjemahkan ke dalam bahasa Urdu, bahasa Turki dan bahasa Melayu. Jadi, pembaharuan Syeh Muhammad Abduh dalam berbagai bidang ilmu pengetahuan, khususnya pembaharuan pendidikan sangat mempengaruhi generasi berikutnya, hingga sampai sekarang ide dan gagasannya yang bernas itu telah dapat mengantarkan generasi berikutnya ke ranah kebebasan berpikir, sehingga banyak sarjanawan yang menilai, baik sarjanawan dari Timur maupun sarjanawan dari Barat, bahwa pemikran Abduh tentang pendidikan dinilai sebagai awal dari kebangkitan umat Islam di awal abad ke-20.

Pemikiran Syeh Muhammad Abduh yang disebarluaskan oleh muridnya Muhammad Rasyid Ridha melalui tulisannya di majalah “ al-Manar “ dan “ al'Urwah al-Wusqa “ menjadi rujukan para tokoh pembaru dalam dunia Islam, sehingga berbagai negara Islam muncul gagasan mendirikan sekolah-sekolah dengan menggunakan kurikulum seperti yang dirintis oleh Syeh Muhammad Abduh.

Demikian pula, pemikiran Syeh Rasyid Ridha, kemungkinan terjadinya reformasi pada tahun 1997/1998 di Indonesia juga diilhami oleh pemikiran Syeh Muhammad Abduh dan Syeh Rasyid Ridha.Secara faktual, kedua tokoh ini menjadi bagian penting dalam silabus perkuliahan S-1, S-2, dan S-3, terutama di perguruan tinggi Islam.

Secara psikologis, hal ini memberi pengaruh dan kontribusi pemikiran bagi dosen dan mahasiswa, terutama kebebasan berpendapat.Pengaruh pemikiran pembaruan Syeh Rasyid Ridha dan Syeh Muhammad Abduh, terasa sampai ke

\footnotetext{
${ }^{18}$ Jalaluddin dan Usman Said, " Filsafat Pendidikan Islam Konsep dan Perkembangan Pemikrannya ", ( Jakarta : PT. Raja Grafindo Persada, 1994). hlm 156
} 
Indonesia.Ide-ide yang terkandung dalam majalah Al-Manar, khususnya mengenai pemberantasan bid'ah dan khurafat, banyak mengilhami timbulnya gerakan pembaharuan di Indonesia.

Bukti-bukti yang dapat dikemuakan sebagai adanya pengaruh ide-ide Syeh Rasyid Ridha di Indonesia, antara lain : terbitnya majalah "al-Munir" di Padang Sumatera Barat yang dikelolah oleh ulama-ulama yang pernah belajar di Mekah. Majalah ini, berita-berita yang dimuat dalam 32 Jalaluddin dan Usman Said, “ Filsafat Pendidikan Islam Konsep dan Perkembangan Pemikrannya“, (Jakarta : PT. Raja Grafindo Persada, 1994).

Para ulama Indonesia banyak yang tertarik untuk membaca majalah "alManar“, baik semasa mereka berada di Mekah maupun setelah kembali ke Indonesia. Hal ini, ditandai dengan munculnya pertanyaan ulama Indonesia terhadap Rasyid Ridha melalui "al-Manar" mengenai ukhwah islamiyah, nasionalisme dan patriotisme dalam pandangan Islam. ${ }^{19}$ Dengan demikian, pembaruan di Indonesia juga diilhami oleh pemikiran Syeh Muhammad Abduh dan Syeh Rasyid Ridha, yang pada akhirnya, pembaharuan yang dilancarkan melalui majalah Al-Munir juga mendapat serangan dari kaum tua atau kaum tradisional.

Hal ini, dikenal di Sumatra Barat, perbedaan pendapat yang paling krusial yaitu, antara kaum tua dengan kaum muda.Demikian pengaruh pemikiran kedua tokoh mujaddid ini yang banyak memberikan kontribusi bagi pembaruan pendidikan generasi berikutnya. Diluar cakupan tulisan ini untuk membahas pemecahan berbagai masalah amat kompleks yang dihadapi pendidikan tinggi Islam merupakan cermin yang seyogyanya menimbulkan refleksi, yang pada gilirannya akan menggerakkan upaya-upaya kreatif dalam kerangka membangun kembali peradaban Islam melalui lembaga pendidikan.

Sebaiknya, kedua tokoh ini patut direspons pembaruan pemikirannya, agar pendidikan tetap berbenah diri, berinovasi yang terus mengadakan perubahan.Apalagi tantangan abad ke-21 ini, bagaimanapun, menuntut respons yang tepat dari sistem pendidikan Islam secara keseluruhan. Jika umat Islam, termasuk Indonesia tidak hanya ingin sekedar surve atau studi perbandingan di

\footnotetext{
${ }^{19}$ Hafiz Dasoeki, Ensiklopedi Islam, Jilid III, (Jakarta1995). Hlm 225
} 
tengah persinggahan global yang semakin tajam dan ketat, tetapi juga berharap mampu tampil di depan, maka reorientasi pemikiran mengenai pendidikan Islam dan restrukturisasi sistem dan kelembagaan jelas merupakan keniscayaan. Cara pandang yang mengesampingkan IPTEK tampak tidak bisa dipertahankan.Kini peluang itu, telah terbuka pintunya untuk menuju masyarakat yang bertamaddun dengan ipteknya setelah dimulai pula pembaruan pendidikan Islam, misalnya IAIN berubah ke UIN, sebuah pembaruan yang memberikan anak kunci untuk membuka pintu pembaruan dengan selebar-lebarnya.

\section{Penutup}

Apabila dibandingkan pembaruan pemikiran Muhammad Abduh dan Muhammad Rasyid Ridha, akan lebih banyak terdapat kesamaan pembaruan pemikirannya. Hal ini, disebabkan hubungan murid dengan guru. Perbedaan yang dapat disimpulkan, bahwa Abduh lebih liberal, sedangkan Rasyid Ridha masih terikat oleh pemikiran orang lain, seperti Imam Ahmad bin Hambali dan Ibnu Taimiyah. Ridha lebih banyak sebagai Abduh dan sebagai Jamaluddin alAfghani. Kendatipun demikian, Rasyid Ridha, di samping lebih banyak tertarik ke politik, dan banyak pula mengulas ide dan gagasan gurunya, dan ia telah berhasil mengembangkan pembaruan pemikiran pendidikannya melalui majalah al-Manar-nya dan melalui buku tafsir yang dirintis oleh Abduh dan dilanjutkan oleh Ridha, yaitu tafsir alManar. Sekarang ide-ide yang bernas itu telah tersebar ke dunia Islam, termasuk Indonesia. Berkat munculnya pembaruan pendidikan kedua tokoh ini, sekarang negara-negara Islam sudah memakai sistem, metode dan kurikulum 


\section{DAFTAR PUSTAKA}

A. Athaillah, Aliran Akidah Tafsîr al-Manar, (Banjarmasin: Balai Penelitian IAIN Antasari, 1990)

Abdillah F. Hasan, Tokoh-Tokoh Mashur Dunia Islam (Surabaya: Jawara Surabaya, 2004)

Ahmad Izzan, Metodologi Ilmu Tafsir(Bandung: Tafakur, 2011)

Charles Kurzman, Wacana Islam Liberal (Jakarta: Paramadina, 2001)

Hafiz Dasoeki, Ensiklopedi Islam, Jilid III, (Jakarta :1995)

Ilyas Daud, Pemikiran Syeh Muhammad Abduh Tentang Al-Quran Tafsir, Jurnal Ushuluddin dan Pemikiran Islam Farabi,Vol. 10 No. 1 (Juni 2013)

Imam Muhsin, Perubahan Budaya dalam Tafsir Al-Quran: Telaah Terhadap Penafsiran Syeh Muhammad Abduh dalam Tafsir Al-Manar, Jurnal Thaqafiyyat, Vol. 16 No. 2 (Desember 2015)

Jalaluddin dan Usman Said, "Filsafat Pendidikan Islam Konsep dan Perkembangan Pemikrannya”,,( Jakarta : PT. Raja Grafindo Persada, 1994)

Luk-Luk Nur Mufidah, Konsep Pendidikan Islam Perspektif Filosof Muslim Dan Praktisi Abad Modern: Syeh Muhammad Abduh dan Muhammad Iqbal, Jurnal Ilmu Tarbiyah At-Tajdid, Vol. 2 No. 2, (Juli 2013)

Makrum, Teologi Rasional: Telaah atas Pemikiran Kalam Syeh Muhammad Abduh, JurnalStudi Keislaman Ulumuna, Vol. XIII No. 2 (Desember 2009)

Maslina Daulay, Inovasi Pendidikan Islam Syeh Muhammad Abduh, Jurnal Ilmu Pendidikan dan Keislaman Darul Ilmi, vol.01 No. 02 (Juli 2013)

Muhaimin, Pembaharuan Islam: Repleksi Pemikiran Rasyid Ridha dan Tokoh-Tokoh Muhammadiyah, (Yogyakarta: Pustaka Dinamika, 2000)

Muhammad Yusran Asmuni, Pengantar Studi Pemikiran dan Gerakan Pembaharuan dalam Dunia Islam, (Surabaya : al-Ikhlas, 1994)

Nasrudin Yusuf, Perbandingan Pemikiran Syeh Muhammad Abduh dan Rasyid Ridho tentang Pendidikan, Jurnal Sosial Budaya, Vol. 8, No. 01 (Januari-Juni 2011)

Rif'at Syauqi Nawawi, Rasionalitas Tafsir Syeh Muhammad Abduh (Jakarta: aramadina, 2002) 
Risan Rusli, Pembaharuan Pemikiran Modern Dalam Islam (Jakarta: Rajawali Press, 2014) 